\title{
Hearing Loss after Discontinuing Secondary Prophylaxis for Cryptococcal Meningitis: Relapse or Immune Reconstitution?
}

\author{
N. Khanna, R. Nüesch, C. Buitrago-Tellez, M. Battegay, H.H. Hirsch
}

\begin{abstract}
Relapse and immune reconstitution syndrome are difficult to distinguish in HIV-infected patients treated with antiretroviral therapy (ART). We report on a 26 -year-old HIV-infected male (CDC C3) with hearing loss on the right side 2 months after discontinuing secondary prophylaxis for cryptococcal meningitis. CD4 cell counts had increased from $32 / \mu \mathrm{l}$ to stable counts $>200 / \mu \mathrm{l}$ for the preceding 6 months on ART but HIV replication was not fully suppressed (7,000 copies/ $\mathrm{ml}$ ). Magnetic resonance imaging identified lesions at the origin of the right cranial nerve VIII. Lumbar puncture revealed monocytic pleocytosis, slightly increased protein, but normal glucose and lactate levels, negative microbiological studies. Fluconazole was restarted and a new ART regimen was started in order to fully suppress HIV replication. Clinical and radiological signs were reversible during follow-up, and secondary prophylaxis was stopped after 6 months without adverse events. We review 26 published cases of cryptococcal infections with immune reconstitution syndrome and highlight the distinguishing features.
\end{abstract}

Infection 2006; 34: 163-168

DOI 10.1007/s15010-006-4042-y

\section{Case Report}

A 26-year-old male from Thailand presented with headache and fever to our outpatient department. Cryptococcal meningitis and pneumonia was diagnosed as well as HIV-1 infection CDC C3 (CD4 cell counts of 32/ $\mu$; HIV viral load of 89,000 copies/ml [4.9 log 10]). Cryptococcus neoformans antigen was positive in blood $(1: 1,024)$. Computer scan of the neurocranium was unremarkable. In the cerebrospinal fluid (CSF), pleocytosis with $507 / \mu \mathrm{l}$ polymorphs, elevated lactate $(3.4 \mathrm{mmol} / \mathrm{l})$, elevated protein $(747 \mathrm{mg} / \mathrm{l})$ and C. neoformans was identified by culture. The patient was treated with amphotericin-B and flucytosine. The clinical condition improved, and antigen titers decreased. Secondary prophylaxis with fluconazole $400 \mathrm{mg}$ daily was administered as well as trimethoprim/sulfamethoxazole (TMP/SMX) three times weekly as primary prophylaxis for Pneumocystis carinii (jiroveci). ART was initiated consisting of stavudine, lamivudine and nelfinavir (Figure 1A). The HIV-RNA viral load decreased by $2 \log 10$ and CD4 cell counts increased to $234 / \mu l$ over the following 6 months. However, HIV replication was sub-optimally suppressed with viral loads around 2,000 copies/ml. ART was switched to didanosine, lamivudine and nevirapine but without significant improvement. After 9 months of stable CD4 cell counts

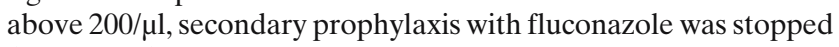
(Figure 1A). Two months later, the patient presented with sudden hearing loss on the right side. The clinical examination was otherwise unremarkable and there was no evidence of vertigo. The audiogramm revealed right-sided central hearing loss at 1,000 Hz. Magnetic resonance imaging of the brain showed multiple small

\section{Introduction}

The discontinuation of secondary prophylaxis for cryptococcal meningitis is considered safe in HIV-infected patients on highly active antiretroviral therapy (ART) with stable CD 4 cell counts $>100$ cells $/ \mu \mathrm{l}$. This is supported by data from prospective studies [1], cohort studies [2] and summarized in current guidelines [3]. However, despite clinical success and improved CD4 counts, paradoxical worsening of the clinical condition has been observed in some cases. The differential diagnosis includes relapse or immune reconstitution syndrome, which are difficult to distinguish from one another $[4,5]$.

\author{
N. Khanna, M. Battegay, H.H. Hirsch (corresponding author) \\ Infectious Diseases and Hospital Epidemiology, Dept. of Internal \\ Medicine, University Hospital Basel, Petersgraben 4, CH-4031 Basel, \\ Switzerland; Phone: (+41/61) 265-5053, Fax: -3198 \\ e-mail: hans.hirsch@unibas.ch \\ R. Nüesch \\ Outpatient Dept. of Internal Medicine, University Hospital Basel, Basel, \\ Switzerland \\ C. B.-Tellez \\ Neuroradiology, University Hospital Basel, Basel, Switzerland \\ H. H. Hirsch \\ Division of Molecular Diagnostics, Institute for Medical Microbiology, \\ Dept. of Clinical \& Biological Sciences, University of Basel, Basel, \\ Switzerland
}

Received: March 18, 2004 - Revision accepted: March 14, 2006 
A
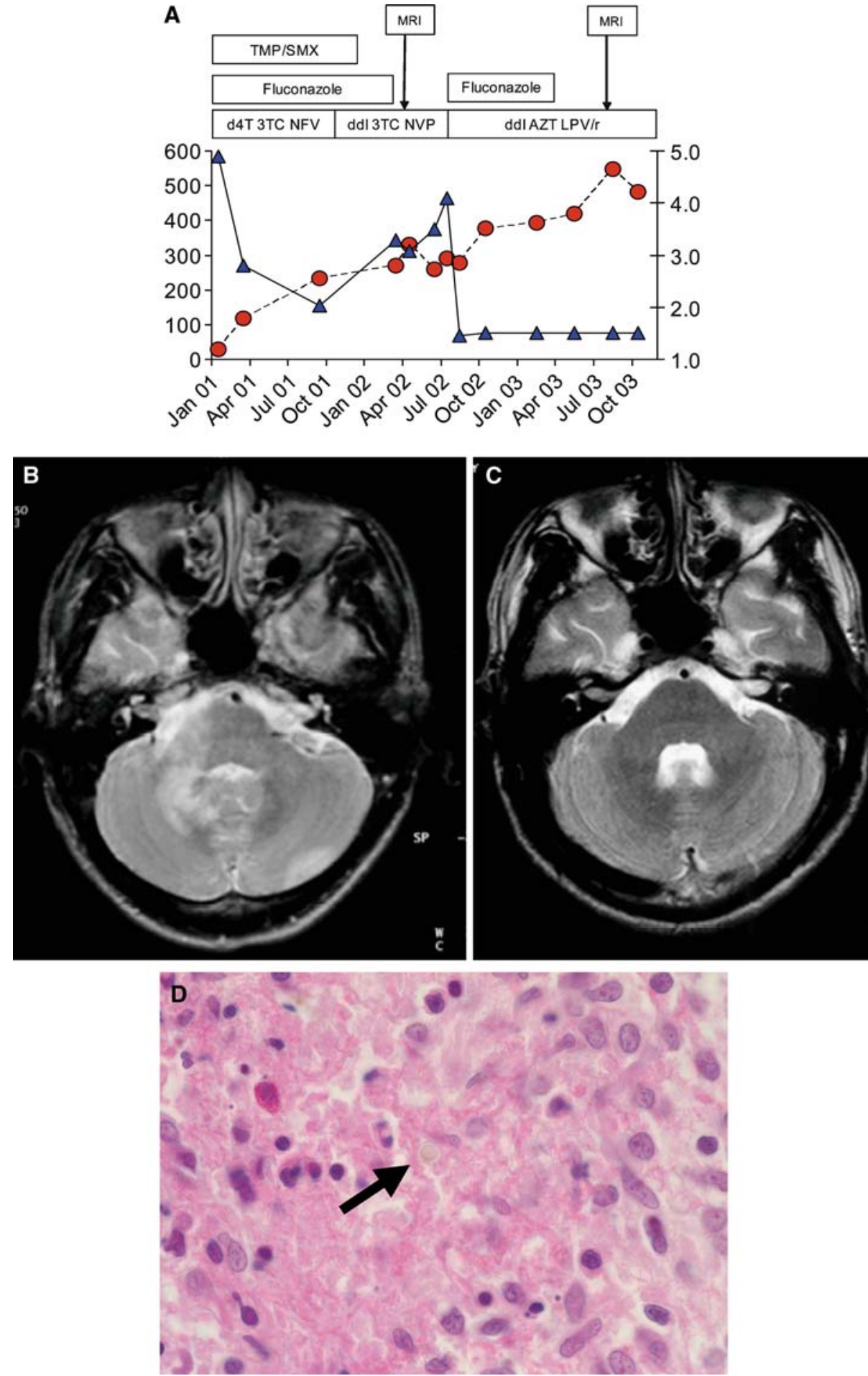

Figure 1. A) Time course of HIV surrogate markers (CD4 cell counts, circles, left axis; HIV viral load in $\log 10$, triangels, right axis), drug treatment in boxes (stavudine, d4T; lamivudine, $3 \mathrm{TC}$; zidovudine, AZT; nelfinavir, NFV; didanosine, DDI; nevirapine, NVP; lopinavir/ritonavir, LPV/r) and MRI in boxes. B) T2-weighted MRI of the head at diagnosis showing hyperintense lesion with edema in the right cerebellum and in the brain stem near the meatus acusticus internus. C) T2-weighted MRI of the head 9 months later showing dissolved lesion and edema in the right cerebellum and in the brain stem near the meatus acusticus internus. D) Lymph node histology showing granuloma with Cryptococcus neoformans (culture negative, antigen positive). contrast enhancing lesions with edema in the left and right cortex and a major lesion in the right cerebellum near the root of the eighth cranial nerve which also emerged in $\mathrm{T} 2$ weigted imaging (Figure $1 \mathrm{~B}$ ). In the CSF, monocytic pleocytosis $(16 / \mu \mathrm{l})$, low lactate $(1.3 \mathrm{mmol} / \mathrm{l})$, low glucose $(2.9 \mathrm{mmol} / \mathrm{l})$ and normal protein levels $(480 \mathrm{mg} / \mathrm{l})$ were detected. Bacterial and fungal culture remained negative. Also, negative results were obtained for cryptococcal antigen, cysticercosis antibodies, and PCR studies specific for M. tuberculosis, cytomegalovirus, polyomavirus JC, Toxoplasma gondii, and Epstein-Barr virus. The differential diagnosis included relapsing cryptococcal infection or immune reconstitution syndrome. Fluconazole was restarted (400 mg/day) HIV resistance testing was performed and ART was changed accordingly to zidovudine, didanosine and lopinavir/ ritonavir. The HIV-RNA viral load dropped under the detection limit (Figure 1A). Six weeks later, hearing loss was unchanged, but painful cervical lymphadenopathy developed. Biopsy of a cervical lymph node showed granulomas with cryptococci (Figure 1D). Cultures from lymph tissue remained negative, but Cryptococcus antigen was detectable in lymph node extracts. After 3 months, hearing improved and decreasing lesion intensity was noted in the MRI (Figure 1C). After 12 months, the CD4 cell counts measured 392/ $\mu$ l and the HIV-RNA viral load remained $<50$ copies $/ \mathrm{ml}$. Fluconazole was discontinued and no signs of relapse occurred during a followup of 30 months. Audiogram confirmed a near complete recovery.

\section{Discussion}

Central neurological symptoms (central hearing loss) and extensive MRI lesions were unexpected in view of adequate antimicrobial therapy and stable CD 4 cell counts above $200 / \mu \mathrm{L}$ for more than 6 months. Although we could not diagnose ongoing cryptococcal disease, relapse had to be considered. On the other hand, CSF pleocytosis and contrast enhancement in MRI rendered immune reconstitution 


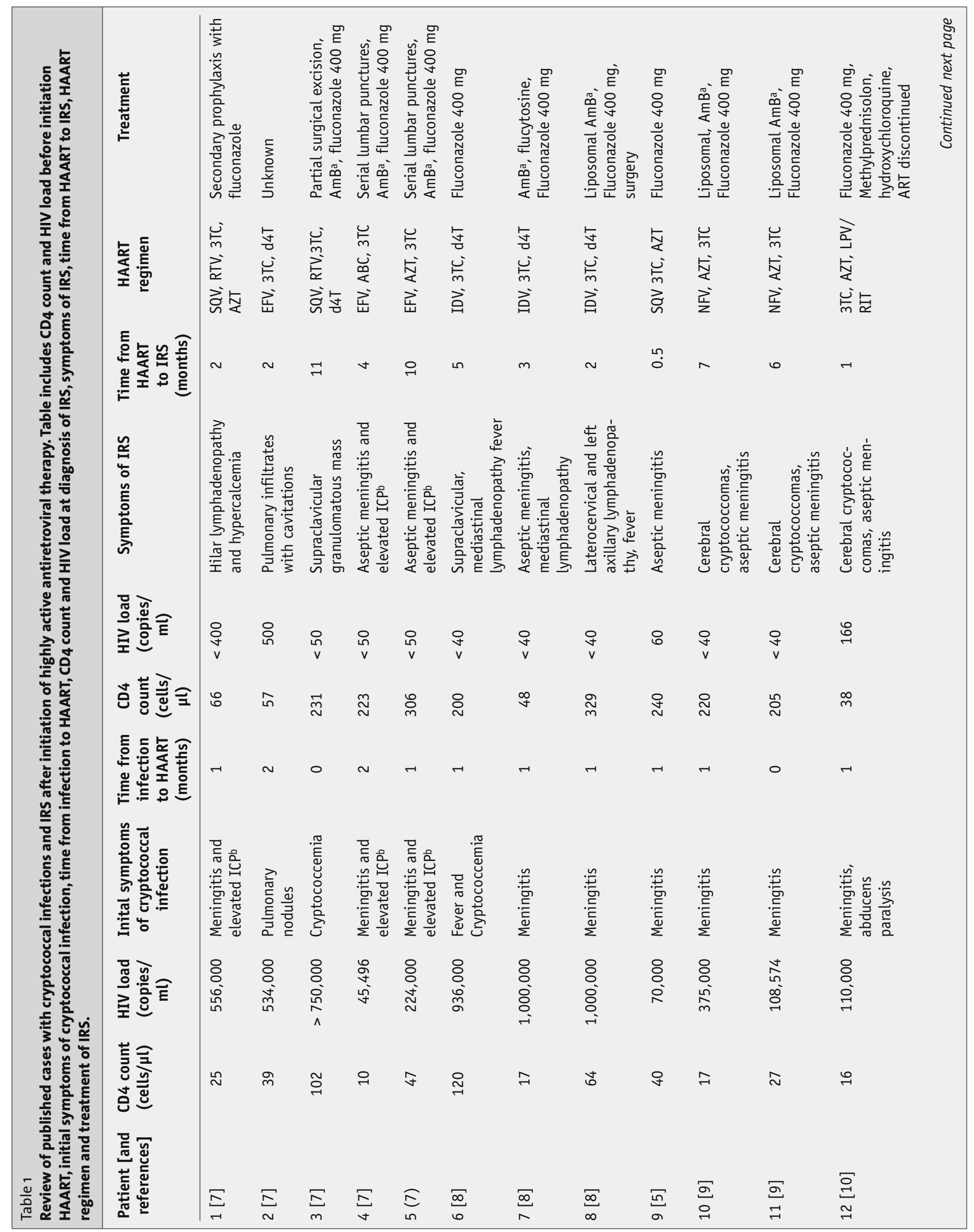




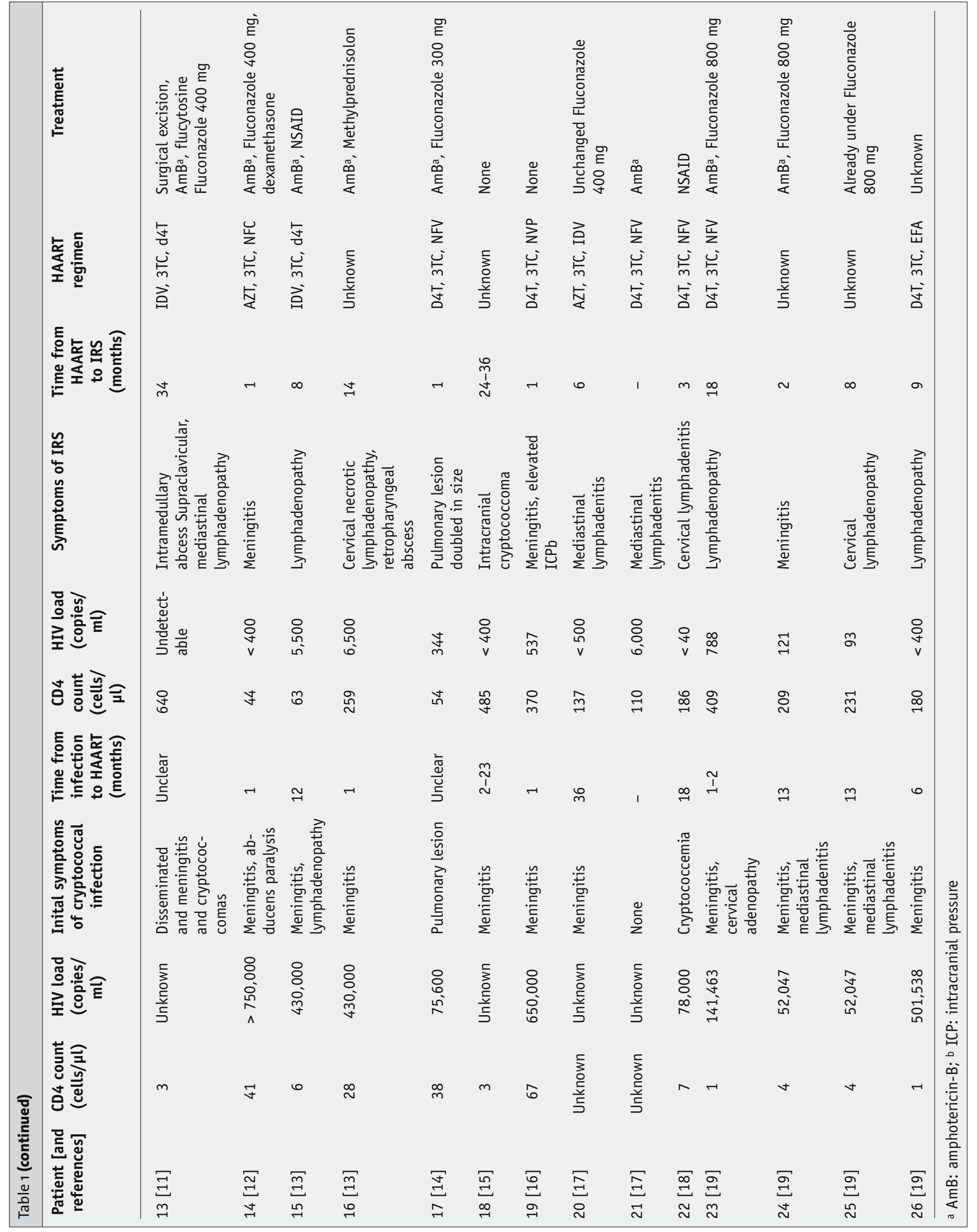


syndrome another likely diagnosis. The subsequent onset of granulomatous lymphadenitis with non-viable C. neoformans also supported this hypothesis, but the long time of onset of more than 6 months after starting ART is unusual. In the literature, variable durations of 5 days to 34 months have been reported with increases in CD4 cell counts ranging from 3 to $637 / \mu \mathrm{l}$ (Table 1 [5, 7-19]). In some cases, IRS may in fact unmask hitherto undiagnosed cryptococcosis [5]. Table 1 lists 26 published cases with cryptococcal infections that developed an IRS after initiation of highly active antiretroviral therapy [5, 7-19]. At the time when IRS developed the CD4 count increased in 21 patients $>$ twofold and viral load decreased $>2 \log 10$ copies $/ \mathrm{ml}$. Similar to our case, cryptococcal relapse could not be excluded in 20 patients who were therefore treated with antifungal therapy (Amphothericin B or high dose fluconazole) and secondary prophylaxis. In five patients, inflammatory treatment with steroids or non steroidal anti-inflammatory drugs was administered. All patients recovered from IRS. No significant correlation between initial signs and symptoms and the subsequent manifestation of IRS are apparent.

IRS occurs in $10-30 \%$ of patients treated with ART and is associated a variety of microbial and non-microbial antigens. Often, initial CD4 cell counts are very low and briskly increase after starting ART [4]. Mycobacterial and cryptococcal antigens are frequently implicated in IRS. Indeed, a recent study found C. neoformans-related IRS in $30 \%$ of HIV-patients [6]. Compared to patients without IRS, patients with C. neoformans-related IRS had a lower HIV viral load, higher CD4 cell count, a higher CSF-opening pressure, higher mononuclear pleocytosis and lower cryptococcal antigen titer in the CSF. However, clinical signs and symptoms were not specific. Antifungal treatment was administered in all cases which emphasizes the clinical dilemma of suspected relapse versus IRS. Of note, neither relapse nor immune reconstitution was reported in a recent prospective study [1]. All patients in this study had optimally suppressed HIV viral loads of $<50$ copies/ $\mathrm{ml}$. One may speculate whether sub-optimally suppressed HIV replication in our patient may have preferentially infected and hence, deleted the Cryptococcus-specific CD4 cells which were activated by abundant antigen. The hypothesis may account for a true relapse despite CD4 cell counts $>200 / \mu$ l and may explain the initial signs and symptoms in our patient. Possibly, discontinuation of secondary prophylaxis may bear a higher risk in sub-optimally suppressed HIV-patients.

\section{References}

1. Vibhagool A, Sungkanuparph S, Mootsikapun P, Chetchotisakd P, Tansuphaswaswadikul S, Bowonwatanuwong C, Ingsathit A: Discontinuation of secondary prophylaxis for cryptococcal meningitis in human immunodeficiency virus-infected patients treated with highly active antiretroviral therapy: a prospective, multicenter, randomized study. Clin Infect Dis 2003; 36: 1329-1331.

2. Kirk O, Reiss P, Uberti-Foppa C, Bickel M, Gerstoft J, Pradier C, Wit FW, Ledergerber B, Lundgren JD, Furrer H: European HIV Cohorts. Safe interruption of maintenance therapy against previous infection with four common HIV-associated opportunistic pathogens during potent antiretroviral therapy. Ann Intern Med 2002; 137: 239-250.

3. Kaplan JE, Masur H, Holmes KK: Guidelines for preventing opportunistic infections among HIV-infected persons-2002. Recommendations of the U.S. Public Health Service and the Infectious Diseases Society of America 639. MMWR Recomm Rep 2002; 51: 1-52.

4. Hirsch HH, Kaufmann G, Sendi P, Battegay M: Immune reconstitution in HIV-infected patients. Clin Infect Dis 2004; 38: 1159-1166.

5. Woods ML, MacGinley R, Eisen DP, Allworth AM: HIV combination therapy: partial immune restitution unmasking latent cryptococcal infection. AIDS 1998; 12: 1491-1494.

6. Shelburne SA 3rd, Darcourt J, White AC Jr, Greenberg SB, Hamill RJ, Atmar RL, Visnegarwala F: The role of immune reconstitution inflammatory syndrome in AIDS-related Cryptococcus neoformans disease in the era of highly active antiretroviral therapy. Clin Infect Dis 2005; 40: 1049-1052.

7. Jenny-Avital ER, Abadi M: Immune reconstitution cryptococcosis after initiation of successful highly active antiretroviral therapy. Clin Infect Dis 2002; 35: e128-e133.

8. Trevenzoli M, Cattelan AM, Rea F, Sasset L, Semisa M, Lanzafame M, Meneghetti F, Cadrobbi P: Mediastinitis due to cryptococcal infection: a new clinical entity in the HAART era. J Infect 2002; 45: $173-179$.

9. Cattelan AM, Trevenzoli M, Sasset L, Lanzafame M, Marchioro $U$, Meneghetti F: Multiple cerebral cryptococcomas associated with immune reconstitution in HIV-1 infection. AIDS 2004; 18 : 349-351.

10. Boelaert JR, Goddeeris KH, Vanopdenbosch LJ, Casselman JW: Relapsing meningitis caused by persistent cryptococcal antigens and immune reconstitution after the initiation of highly active antiretroviral therapy. AIDS 2004; 18: 1223-1224.

11. Rambeloarisoa J, Batisse D, Thiebaut JB, Mikol J, Mrejen S, Karmochine M, Kazatchkine MD, Weiss L, Piketty C: Intramedullary abscess resulting from disseminated cryptococcosis despite immune restoration in a patient with AIDS. J Infect 2002; 44: 185-188.

12. King MD, Perlino CA, Cinnamon J, Jernigan JA: Paradoxical recurrent meningitis following therapy of cryptococcal meningitis: an immune reconstitution syndrome after initiation of highly active antiretroviral therapy. Int J STD AIDS 2002; 13: 724-726.

13. Blanche P, Gombert B, Ginsburg C, Passeron A, Stubei I, Rigolet A, Salmon D, Sicard D: HIV combination therapy: immune restitution causing cryptococcal lymphadenopathy dramatically improved by anti-inflammatory therapy. Scand J Infect Dis 1998; 30: 615-616.

14. Legendre U, Battegay M, Nuttli I, Dalquen P, Nuesch R: Simultaneous occurence of 2 HIV - related immunereconstitution diseases after initiation of highly active antiretroviral therapy. Scand J Infect Dis 2001; 33: 388-389.

15. Breton G, Seilhean D, Cherin P, Herson S, Benveniste O: Paradoxical intracranial cryptococcoma in a human immunodeficiency virus-infected man being treated with combination antiretroviral therapy. Am J Med 2002; 113: 155-157. 
16. Cinti SK, Armstrong WS, Kauffman CA: Case report. Recurrence of increased intracranial pressure with antiretroviral therapy in an AIDS patient with cryptococcal meningitis. Mycoses 2001; 44: 497-501.

17. Lanzafame M, Trevenzoli M, Carretta G, Lazzarini L, Vento S, Concia E: Mediastinal lymphadenitis due to cryptococcal infection in HIV-positive patients on highly active antiretroviral therapy. Chest 1999; 116: 848-849.
18. Manfredi R, Pieri F, Pileri SA, Chiodo F: The changing face of AIDS-related opportunism: cryptococcosis in the highly active antiretroviral therapy (HAART) era. Case reports and literature review. Mycopathologia 1999; 148: 73-78.

19. Skiest DJ, Hester LJ, Hardy RD: Cryptococcal immune reconstitution inflammatory syndrome: report of four cases in three patients and review of the literature. J Infect 2005; 51: e289-e297. 